\title{
Pontes ad Fontes - Bridges to Sources
}

\section{Kadri Novikov, Anni Arukask}

The 2015 Colloquium Balticum took place at the University of Tartu from 5 to 7 November. This annual colloquium first held in 2001 at Lund University, has continued to bring together Antiquity scholars from Sweden, Germany, Estonia, Latvia, Lithuania, Poland, Finland and Russia. While participants come mainly from classical studies, researchers from a variety of disciplines have also recognised the conference's merit. Over the years, the programme has addressed disciplines such as philosophy, Greek and Latin literature, as well as, for instance, the Greek and Latin education or the influences of ancient mythology in contemporary literature. The delivered papers are authored by both recognised scholars and by $\mathrm{MA}$ - and $\mathrm{PhD}$-students presenting their first academic achievements.

The subtitle of this year's Colloquium Balticum XIV Tartuense was Pontes ad fontes (Bridges to Sources), aiming to draw attention to methodological questions in researching Classical Antiquity and reception of ancient culture. As expressed in the conference invitation, a wide variety of activities could be considered Pontes (Bridges) to Antiquity: discovery, interpretation, translation, commentaries and teaching of ancient heritage. This subtitle offered an opportunity to include papers on poetry and poetics, methods and possibilities of textual analysis, themes and forms of ancient poetry in contemporary literature, and so on. We will give a short overview of such papers presented during the eight sessions on the colloquium in Tartu.

During the first session on 5 November, Anna Strode from the University of Latvia discussed the themes of 17th century occasional poetry in Riga and their relation to the history of Livonia. Due to the domination of Swedish Empire at the time in Livonia, the level of education improved, and in 1631 the Riga Academic Gymnasium was founded and soon scientific texts started to appear. Hand in hand with the growing importance of Latin and Greek language in education, occasional poetry in these languages began to bloom. In order to graduate from the Gymnasium, students had to take part in various disputations (disputationes) held in school as well as in public. Texts of these disputations were printed before the disputations themselves took place; the printed versions included occasional poems congratulating the respondents (that is, students of the Gymnasium, who were the authors of the disputations), which were added to the end of the texts. Strode described how the main 
themes of occasional poems appended to theological disputations concerned man and God, piety and belief, the kingdom of God, and heresy. Therewith, the mentioning of Greek gods was not regarded as heresy as they were seen as mythological characters and portrayals of certain values. The purpose of writing this kind of poetry was to express the writers' beliefs, to congratulate the addressee, and to give indirect instructions to potential listeners, combined into one short poem. Sometimes the content of the poem was directly influenced by the theme of the disputation, and even direct quotations occurred. Occasional poems appended to philosophical disputations, however, concerned themes such as virtue, justice, honesty, modesty, and they were less often influenced by the theme of the disputation. Many allusions to ancient philosophy were made in which education was praised as a precondition of a happy life.

In the second session, Xenia Hering from the University of Marburg focused on the sources of the comic in Latin comedy and presented Plautus (on the basis of the analysis of his Pseudolus) as the borderline author of Italian improvisational theatre and the Greek New Comedy. Plautus accepts the principles of the New Comedy, but takes the action to the Roman environment and makes some modifications, often breaking the consistency of the storyline (discontinuity dominates instead of linearity of the storyline) and emphasising pathos instead of logos. In his comedy, elements of the Italian improvisational theatre (Fabula Atellana and mimus) can be observed. For instance, in comic situations more emphasis is put on dialogues, contestations, word-plays, in order to play to the audience who was accustomed to the entertainment of the improvisational theatre. However, the comic is not inserted only for amusement, but is also integrated into the events in the storyline. By analysing three passages from Plautus' Pseudolus, Hering described how it is characteristic to Plautus' style to break the standard storyline in order to insert a comic dialogue or a comic situation, which can be regarded as a digression and a static element. It is highlighted from the rest of the storyline with its absurdity and sometimes helps to create suspension. Furthermore, humour can be seen as dominating over the logical movement of the storyline, occasionally intensified by the meta-theatrical effects (for example, characters watching others and commenting on their actions). She showed how comic situations were also used to expose the true nature of characters. Thus, Plautus can be regarded as the creator of a unique form of entertainment merging two different forms of comedy which played to the expectations and taste of his audience.

The next speaker in this session was Manuel Reith, also from the University of Marburg, who analysed the function of fables in the poetry of Horace. Compared to works of earlier Latin authors, whose texts included only one or two fables, we can see a much more frequent occurrence of fables in the 
works by Horace, especially in his Satires and Epistles. In the Satires, as a combination of different motives, texts and themes, the fables stand out as a vivid element of composition. Difference of the function of fables in Horace from earlier authors was demonstrated by Reith with the example of the fable The Bird in Borrowed Feathers, known also from Phaedrus, which occurs in Horace's Epistles 1.3.18-20. Horace accuses the poet Celsus in plagiarising other authors, and encourages him to look for his own strength. To this warning Horace adds allusion to the fable about the bird. Here it can be seen that Horace adjusts the use of the fable to his own intentions, and does not bring it as a mere example or literary illustration according to the rhetorical exercises or progymnasmata. In this epistle Horace does not bring forth the common aspect of accepting oneself as one is - instead, he emphasises the aspect of stealing. Through the allusion to the fable, the allegation becomes part of the wit, created through ambiguity of the meaning of words in the previous verses, but is at the same time strengthened by the allusion. Hereby, it becomes clear, that Horace uses fables not as mere stories for children or as literary ornamentation any more, but as something much more complex and purposeful.

On 6 November, in the third session of Colloquium Balticum Tartuense, Kadri Novikov, from the University of Tartu, discussed the function and form of narrative speeches in the ancient Greek novel Leucippe and Clitophon by Achilles Tatius. In the novel, 10 such speeches function as internal analepseis (looking back to events in the main storyline), and one speech as a mixed analepsis (events narrated in it start before the main storyline, but merge with it eventually). Thematically, Novikov identifies five groups of speeches: description of the death of the beloved; explanations of the apparent deaths of the protagonist Leucippe; speeches preparing the reader for the following events; speeches advancing the plot; and, speeches leading towards happy ending. The occurrence of rhetorical figures was also analysed in these speeches, with the results showing a similarity between speeches describing the death of the beloved, and in others the similarities less conspicuous. However, within longer speeches sections with different functions can be distinguished for instance, purely narrative, or descriptive, or sections quoting dialogues between other characters. In all these sections a slightly different use of rhetorical figures can be discerned, as within the novel as a whole (for instance the combination of structural, lexical and sound-repetitions is often used in descriptive sections, whereas in purely narrative passages the keywords are highlighted mainly with the help of lexical and sound-repetitions). Thus, we can regard narrative speeches, themselves part of the larger work, as sort of "micronarratives" combining different forms and functions and expressed using different poetical devices. 
Next, Annika Mikkel, also from the University of Tartu, analysed the occurrences of cursus in the 14th century Italian prose by the example of Vita Nuova and Convivio by Dante Alighieri. The term clausulae in ancient rhetorical theory denotes rhythmical units at the end of sentences, based on specific alternation of short and long syllables. This type of prose rhythm was used by many ancient authors (for instance, Livy, Sallust, Cicero), with their preference to use one or another type of clausula proven by analyses. In time, the word stress became more significant and a type called cursus mixtus, where the quantity as well as word stress were important, was developed. This in turn evolved into Medieval Latin prose rhythm called cursus, where only word stress was important. Four different patterns were used (cursus planus, velox, tardus and trispondaicus), whereas the cursus had to consist of at least two words, the last word had to be at least three syllables long (although some modifications were allowed). Dante Alighieri began to use the cursus also in the new popular language - Italian. The occurrence of cursus had been analysed in Alighieri's Latin books, but Mikkel has begun the analysis of Dante's Italian books Vita Nuova and Convivio. The results show that 59\% of Vita Nuova is written using cursus, whereas cursus planus occurs in $32 \%$ of the text. It is also one of the most natural types in the popular language (together with cursus trispondaicus). A higher occurrence of cursus velox and cursus tardus, however, can be noticed in some chapters, where it may be connected to the theme and content. In the first two books of Dante's Convivio, the use of cursus is rather similar - again cursus velox and tardus, otherwise less used, occur more in some chapters. In conclusion, it can be said, that Dante used cursus rather extensively also in his works in Italian, but adjusts it to the requirements of the natural language, resulting in the dominance of different types of cursus than in Latin prose, where cursus velox was used most extensively.

Session four was entirely devoted to poetry and poetics. Vita Paparinska from the University of Latvia talked about the beginning of the phenomenon of occasional poetry that emerged as a distinct literary genre in the texts of Publius Papinius Statius ( $1^{\text {st }}$ century AD). His collection of occasional poetry, Silvae, consists of 32 poems, which, according to the poet himself, were of improvisational nature, quite long texts written in 1-2 days. However, these poems are full of conscious display of learning, and this claim of the improvisational nature and the rapid composition of these texts should not be taken too earnestly - some of them may have been written due to the wish of the patron, and prepared over a longer period of time. The poems vary in character; there are funerary laments, poems of consolation, for birthdays, a wedding poem, a farewell poem, descriptions, poetic epistles, and so on. As Statius wrote for pay, each occasion covered is directly and concretely 
connected with people of importance in the poet's life, most often but not exclusively dedicated to the patron.

In his presentation, "Construction Poetics and Poetic Constructions: Bridging Between Homer, Blues, and Lihtuanian Folk Songs", Gintaras Dautartas from the University of Vilnius applied construction grammar, combined with the Parry-Lord and Immanent Art theories, to establish a framework for a thorough linguistic and literary analysis of oral formulaic poetry, which he illustrated with examples from such composition-in-performance genres as Lithuanian folk songs, Homer's epics and commercial blues. This model of analysis is currently being developed by Cristóbal Pagán and Mihailo Antović, while Dautartas suggested some improvements to the framework. Dautartas regarded poetic constructions as pairings of form and poetic meaning and/or function. Analysing poetic constructions that all vary in size, complexity and the degree of generalisation in different song genres, he concluded that composition-in-performance is not a fixed attribute, but a gradable feature that can be expressed on a scale. The degree of composition-in-performance among different genres of Lithuanian folk songs is dependent on the type of constructions that are used by the singer. For example, Lithuanian dainos, as well as commercial blues, are mainly (but not entirely) created during their performances and use macroconstructions, which is a learned combination of different constructions with a small amount of modifiable slots. On the other hand, the funeral lamentations use mainly microconstructions and the degree of composition on the spot is higher. In preserved epic poetry we can recognise a wide assortment of constructions and degree of improvisation variety, each performance, however, was probably unique depending on the performer and the context.

Ilona Gorneva from the University of Latvia talked about visual poetry and focused on the example of Mariagrammas (2013), a collection of poems by Leons Briedis (born 1949), where many ancient reminiscences can be found among texts of cultural and historical scenes significant to the Latvian public. Here she illustrated how Briedis introduced ancient culture expressed through ideas, images, visual associations, choice of vocabulary, and so on. The poet stresses the significance of the synthesis in the formation of the collection and in the perception of poetry. These ancient signs have acquired new original forms and meanings in Briedis's interpretation. Many titles of the poems in the collection are Latin sententiae or phrases in Latvian carrying an ancient allusion. In all these cases, the visual shape is an important elaborating detail although some visuals in the collection cannot be unequivocally interpreted. In addition, Briedis has borrowed the axe-shape and numerical organisation from Simias's visual poem Pelekys for a poem on the Trojan horse. However, 
by applying different reading-strategies, one can get two different versions and two different meanings of this one poem. In the poem called Heritage, shaped like two columns under a slogan, ancient reminiscences might be represented in the most powerful manner. The first slogan-shaped line of the poem refers

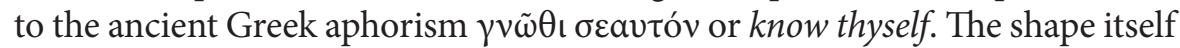
is generally not self-sufficient, the poems preserve rhymes and rhythmic picture, and offer pleasure in reading. However, the visual shape is a detail that matters.

All the papers presented at the Colloquium Balticum Tartuense showed that studying ancient literature and culture is crucial in understanding the sources of our contemporary culture, and each speaker managed to build a small bridge towards this understanding.

The recordings of all the session are available for viewing from the link http://www.uttv.ee/otsing\#sona=colloquium, the programme of the conference together with abstracts can be found from http://www.maailmakeeled. ut.ee/et/programme-colloquium-balticum-xiv-tartuense. 